\title{
Physical capacity of girls with mild and moderate idiopathic scoliosis: influence of the size, length and number of curvatures
}

\author{
Dariusz Czaprowski • Tomasz Kotwicki • \\ Ryszard Biernat · Jerzy Urniaż • Aleksander Ronikier
}

Received: 23 February 2011/Revised: 6 October 2011/ Accepted: 6 November 2011/Published online: 22 November 2011

(C) The Author(s) 2011. This article is published with open access at Springerlink.com

\begin{abstract}
Introduction Idiopathic scoliosis affects the locomotor system; however, it can considerably impair the function of cardiovascular and respiratory systems. The aim of the study was to assess parameters indicating the physical capacity of adolescent girls with mild or moderate idiopathic scoliosis.

Materials and Methods The study included 97 girls, aged 10-18 years: 70 girls, aged $13.84 \pm 2.2$ years, with idiopathic thoracic scoliosis (Cobb angle $10^{\circ}-40^{\circ}$ ) formed the study group and 27 healthy girls, aged $13.2 \pm 1.9$ years, formed the control group. The girls underwent the Physical Work Capacity 170 (PWC170) test on a cycle ergometer based on two 5-min submaximal physical effort events. The maximum oxygen intake was calculated and expressed in $1 / \mathrm{min}$ and $\mathrm{ml} / \mathrm{kg} / \mathrm{min}$. The impact of the curvature angle
\end{abstract}

D. Czaprowski $(\bowtie) \cdot R$. Biernat

Faculty of Physiotherapy, Józef Rusiecki University

College in Olsztyn, Bydgoska 33, 10-243 Olsztyn, Poland

e-mail: dariusz.czaprowski@interia.pl

T. Kotwicki

Department of Pediatric Orthopedics and Traumatology, University of Medical Sciences in Poznań,

28 Czerwca 1958 r., No. 135, 61-545 Poznań, Poland

e-mail: kotwicki@ump.edu.pl

J. Urniaż

Faculty of Physical Education, Józef Rusiecki University

College in Olsztyn, Bydgoska 33, 10-243 Olsztyn, Poland

\section{A. Ronikier}

Department of Biological Basics of Rehabilitation,

Faculty of Rehabilitation, Józef Piłsudski

Academy of Physical Education in Warsaw,

Marymoncka 34, 00-968 Warszawa, Poland value, of the number of vertebrae within the curve and of the number of the curves on the physical capacity parameters was analyzed.

Results The maximal oxygen intake (1/min) and PWC170 (W; W/kg) values were considerably lower in girls with scoliosis of $25^{\circ}-40^{\circ}$ than in the control group. No significant differences were observed between girls with mild scoliosis $\left(10^{\circ}-24^{\circ}\right)$ and the control group. Statistical analysis did not show any significant impact of the number of vertebrae affected by scoliosis and the number of curvatures on $\mathrm{VO}_{2} \max (1 / \mathrm{min} ; \mathrm{ml} / \mathrm{kg} / \mathrm{min})$ and the PWC170 (W) indicator. In the group of girls with scoliosis involving more than nine vertebrae, the PWC170 (W/kg) indicator was significantly lower than in the control group. A similar correlation was observed between girls with double-curved scoliosis and the control group $(p<0.05)$.

Conclusion The maximum oxygen intake and the output during the PWC170 test is lower in girls with moderate scoliosis than in the control group. The value of maximum oxygen intake and output obtained during the PWC170 test in girls with mild scoliosis does not differ significantly from the values obtained in the control group. The number of vertebrae involved in scoliotic deformation and the number of curvatures cause significant decrease in only the relative value of the output obtained during an exercise test.

Keywords Idiopathic scoliosis - Physical capacity

\section{Introduction}

Idiopathic scoliosis (IS) is a multiplane spine distortion of unknown etiology [3, 22]. Spinal and thorax deformities can have impact on the functioning of the cardiovascular 
and respiratory systems $[1,12,13,33]$. In consequence, physical capacity can be reduced $[1,4,10]$.

Physical capacity determines the organism's ability to make a physical effort, to tolerate dysfunctions of endogenous homeostasis caused by the physical effort and to quickly regain balance [3].

For a child to properly develop, a specific level of physical capacity is needed because it is the basis for shaping various motor features. A lowered level of physical capacity and, as a result, a lowered overall performance prevents children from exerting their full biological potential, the consequences of which can be seen in their adult and elderly lives [30].

The most common measure for physical capacity is the maximum oxygen intake $\left(\mathrm{VO}_{2} \mathrm{max}\right)$ which determines the organism's capacity to transport and use oxygen [16, 24, 30]. Among the many factors determining the maximum oxygen intake, there are those that can be disturbed due to idiopathic scoliosis, for example, deformation and decrease of the chest mobility, decrease of capacity or weakness of the respiratory muscles [8, 13, 21].

The study aimed to assess the impact of the curvature angle value, the number of vertebrae in curvatures and the number of curvatures on the physical capacity of girls aged 10-18 with mild and moderate idiopathic scoliosis.

\section{Materials and methods}

Ninety-seven girls, aged 10-18 (70 girls in the study group and 27 in the control group) were examined. The inclusion criteria in the study group were: female, aged 10-18, idiopathic thoracic scoliosis, Cobb angle ranging from $10^{\circ}$ to $40^{\circ}$ on standing frontal radiograph, the absence of contraindications for exercise tests, child's and parents' consent. The study group was divided into two subgroups: (A) mild scoliosis: 42 girls with $10^{\circ}-24^{\circ}$ curves (mean $17.1^{\circ} \pm 4.6$ ) and (B) moderate scoliosis: 28 girls with $25^{\circ}-40^{\circ}$ curves (mean $32.1^{\circ} \pm 4.3$ ). The average number of vertebrae forming scoliosis was 9.4 vertebrae. Thirty-four girls had single thoracic scoliosis, while 36 girls had double right thoracic and left lumbar scoliosis.

The control group (C) was formed by randomly chosen girls who respected the inclusion criteria: aged 10-18, no scoliosis defined as the angle of trunk rotation below $5^{\circ}$ as measured with Bunnell scoliometer, the absence of contraindications for exercise tests, child's and parents' consent.

No differences were found between the three groups (A, B, C) regarding the age, weight and BMI, however difference in height was found (A and B vs. C) (KruskalWallis test) (Table 1).

The PWC170 (Physical Working Capacity) test [3, 19] was used to assess physical capacity. A written consent from parents and the approval of the local ethical commission were obtained. The test was conducted on a MONARK 874 E cycle ergometer (Monark, Sweden). The assessment was based on two 5-min submaximal physical effort events, where the level of effort was such that each event could be concluded with the heart rate (HR) approaching 130 and 150 beats per minute. The heart rate was recorded by means of a POLAR Sport Tester produced by OY (Finland). The average HR values were recorded at the end of each 5-min physical effort, which served to determine the strain output in accordance with PWC170 indicator. The indicator was calculated on the basis of Sjostrand's formula [28]:

$\begin{aligned} \mathrm{PWC} 170= & {[(P 2-P 1) /(\mathrm{HR} 2-\mathrm{HR} 1)] \times(170-\mathrm{HR} 2) } \\ & +P 2\end{aligned}$

Where P1 and P2 are output of subsequent physical efforts expressed in watts (W), HR1 and HR2 are heart rate during a particular strain test.

The value of PWC170 indicator was also expressed in watts per kilogram $(\mathrm{W} / \mathrm{kg})$ to illustrate the relation of PWC170 to weight. Next, $V \mathrm{O}_{2} \max$ was calculated using Karpman's formula [19]:

$V \mathrm{O}_{2} \max (1 / \min )=1.7 \times \mathrm{PWC} 170+1,240$

where $\mathrm{VO}_{2} \mathrm{max}$ is maximum oxygen intake ( $\left.1 / \mathrm{min}\right), 1.7$ and 1,240 are constant values (unsigned), PWC170 is the absolute value (without sign).The results obtained were also specified in relation to weight and expressed in milliliters per kilogram per minute, $R V \mathrm{O}_{2} \max (\mathrm{ml} / \mathrm{kg} / \mathrm{min})$. The results underwent statistical analysis by means of the Statistica 8.1. (StatSoft, USA). Distribution was assessed by way of Shapiro-Wilk's test. The Wald-Wolfowitz, Kruskal-Wallis, and Dunn tests were used as well as
Table 1 Comparison of age, weight, height and $B M I$ in the study (A, B) and control (C) groups

The values presented as mean (SD). Significant difference at a level of $p<0.05$ is in italic

\begin{tabular}{lcccc}
\hline & (A) Mild Cobb & (B) Moderate Cobb & (C) Control & $p$ value \\
& $10^{\circ}-24^{\circ}(n=42)$ & $25^{\circ}-40^{\circ}(n=28)$ & $13.2(1.9)$ & 0.4 \\
\hline Age (years) & $13.76(2.1)$ & $13.97(2.4)$ & $47.0(11.9)$ & 0.06 \\
Weight $(\mathrm{kg})$ & $47.9(8.1)$ & $49.1(9.4)$ & $155.9(9.5)$ & 0.02 \\
Height $(\mathrm{cm})$ & $161.8(8.9)$ & $161.0(9.1)$ & $19.1(3.0)$ & 0.5 \\
BMI $\left(\mathrm{kg} \mathrm{m}^{-2}\right)$ & $18.1(2.1)$ & $18.7(2.3)$ & - & \\
Cobb $\left({ }^{\circ}\right)$ & $17.1(4.6)$ & $32.1(4.3)$ & - & \\
\hline
\end{tabular}


Spearman's correlation of ranks. A value of $p<0.05$ was adopted as the significance level.

\section{Results}

The values of all measured parameters were lower in the scoliosis group than in the control group. However, a significant difference applied only to the relative value of the output obtained during the exercise test (W/kg) (Table 2).

Impact of the angle of thoracic curvature on physical capacity

A significant difference between the analyzed groups ( $p=0.02)$ with regard to $V \mathrm{O}_{2} \max (1 / \mathrm{min})$ was found. Girls with moderate idiopathic scoliosis $\left(25^{\circ}-40^{\circ}\right)$ obtained considerably lower values of $V_{2} \max (1 / \mathrm{min})$ than the controls (Dunn's test).

No significant difference of the maximum oxygen intake in relation to weight $(\mathrm{ml} / \mathrm{kg} / \mathrm{min})$ among the groups: (A) scoliosis $10^{\circ}-24^{\circ}$, (B) scoliosis $25^{\circ}-40^{\circ}$ and (C) control group was found ( $p=0.12$, Kruskal-Wallis test).

Girls with thoracic scoliosis of $25^{\circ}-40^{\circ}$ obtained considerably lower absolute output value during the PWC170 test than girls from the control group ( $p=0.02$, Dunn's test).

Girls with thoracic scoliosis ranging from $25^{\circ}$ to $40^{\circ}$ obtained a significantly lower value of relative output during the PWC170 (W/kg) test for the indicator expressed in relation to weight in comparison with the control group ( $p=0.003$, Dunn's test) (Table 3).

Based on Spearman's correlation of ranks, the relation between the examined parameters and the curvature value was determined. Their values decreased along with increasing thoracic curvature value. However, a weak negative correlation was significant only for the relative output value obtained during the exercise test $(p=0.02)$ (Table 4).

Table 2 Maximum oxygen intake $V \mathrm{O}_{2} \max (1 / \mathrm{min})$, relative maximum oxygen intake $R V \mathrm{O}_{2} \max (\mathrm{ml} / \mathrm{kg} / \mathrm{min})$ and the output obtained in PWC170 test $(\mathrm{W} ; \mathrm{W} / \mathrm{kg})$ in the scoliosis and the control groups (Wald-Wolfowitz test)

\begin{tabular}{lccc}
\hline & $\begin{array}{l}\text { Mild + moderate } \\
(n=70)\end{array}$ & $\begin{array}{l}\text { Control group } \\
(n=27)\end{array}$ & $p$ value \\
\hline$V \mathrm{O}_{2} \max (1 / \mathrm{min})$ & $1.96(0.15)$ & $2.03(0.18)$ & 0.45 \\
$R V \mathrm{O}_{2} \mathrm{max}(\mathrm{ml} / \mathrm{kg} / \mathrm{min})$ & $41.99(8.87)$ & $44.42(8.63)$ & 0.45 \\
$\mathrm{PWC170}(\mathrm{W})$ & $71.05(14.36)$ & $77.35(18.4)$ & 0.79 \\
$\mathrm{PWC} 170(\mathrm{~W} / \mathrm{kg})$ & $1.52(0.41)$ & $1.68(0.29)$ & 0.04 \\
\hline
\end{tabular}

Values expressed as mean (SD). Significant difference is marked in italic
Impact of the number of scoliosis vertebrae on physical capacity

No significant difference between the group of girls with the number of vertebrae below and equal ( $\leq 9$ vertebrae), or above $(>9)$ the average number $(=9)$ and the control group with respect to the maximum oxygen intake expressed in $1 / \mathrm{min}(p=0.06)$, and $\mathrm{ml} / \mathrm{kg} / \mathrm{min}(p=0.38)$, as well as, with respect to the absolute value of the PWC170 indicator (W) $(p=0.06)$ was found (Kruskal-Wallis test). A significant difference between the groups was found for the output obtained during the exercise test $(p=0.01$, Kruskal-Wallis test). Girls with an above average scoliosis length obtained a significantly lower value of PWC170 $(\mathrm{W} / \mathrm{kg}$ ) indicator than girls from the control group (Dunn's test) (Table 5).

Spearmann's rank correlation showed a negative impact of the number of scoliotic vertebrae on the examined parameters; however, with regard to the maximum oxygen intake and the absolute value of the PWC170 indicator, this correlation proved to be insignificant. As for the relative output, a weak negative correlation with the number of scoliotic vertebrae was confirmed (Table 6).

Impact of the number of curvatures on physical capacity

A significant difference between the control group and the girls with single- and double-curve scoliosis was observed with respect to the value of the PWC170 indicator expressed in relation to weight $(\mathrm{W} / \mathrm{kg})(p=0.01$, KruskalWallis test). The girls with double-curve scoliosis had a significantly lower value of the PWC170 indicator expressed in relation to weight $(\mathrm{W} / \mathrm{kg})$ than the girls from the control group (Dunn's test) (Table 7).

\section{Discussion}

Idiopathic scoliosis is a complex three-dimensional deformity of the spine that most commonly occurs in girls, which can be associated with the possibility of abnormal control and modulation of skeletal growth and development [32]. However, it is not only restricted to the motor system but also causes many changes in the functioning of the cardiovascular and respiratory systems [12, 13, 33]. Successful treatment of idiopathic scoliosis is a complex challenge as rapid growth is likely to cause an increase in the spinal curvature [5].

This study attempted to assess the multifactorial impact of mild and moderate idiopathic scoliosis on the physical capacity of girls aged 10-18. For this purpose, the maximum oxygen intake was determined $(1 / \mathrm{min} ; \mathrm{ml} / \mathrm{kg} / \mathrm{min})$ 
Table 3 Comparison of $V \mathrm{O}_{2} \max (1 / \mathrm{min}), R V \mathrm{O}_{2} \max (\mathrm{ml} / \mathrm{kg} / \mathrm{min})$ and $\mathrm{PWC} 170$ index $(\mathrm{W} ; \mathrm{W} / \mathrm{kg})$ in the study (A, B) and control $(\mathrm{C})$ groups

\begin{tabular}{lccccc}
\hline & (A) Mild Cobb & (B) Moderate Cobb & (C) Control & $p$ value & Dunn's test \\
& $10^{\circ}-24^{\circ}(n=27)$ & $25^{\circ}-40^{\circ}(n=42)$ & Moderate $<$ Control \\
$V \mathrm{O}_{2} \max (1 / \mathrm{min})$ & $1.99(0.16)$ & $1.91(0.16)$ & $2.03(0.1)$ & 0.02 & - \\
$R V \mathrm{O}_{2} \max (\mathrm{ml} / \mathrm{kg} / \mathrm{min})$ & $42.98(8.7)$ & $40.5(9.0)$ & $44.41(8.6)$ & 0.12 & Moderate $<$ Control \\
$\mathrm{PWC170}(\mathrm{W})$ & $74.36(16.1)$ & $66.07(9.6)$ & $77.35(18.4)$ & 0.02 & Moderate $<$ Control \\
$\mathrm{PWC170}(\mathrm{W} / \mathrm{kg})$ & $1.59(0.4)$ & $1.41(0.3)$ & $1.68(0.3)$ & 0.003 & \\
\hline
\end{tabular}

The values presented as mean (SD). Significant differences are marked in italic

and the value of output was obtained in the PWC170 test (W; W/kg).

The natural history of untreated severe thoracic scoliosis $\left(\mathrm{Cobb}>100^{\circ}\right)$ revealed increased mortality, related to right heart failure due to congestive lung disease [2]. Hitosugi et al. [17] in the case report of sudden death of a woman with untreated right thoracic and left lumbar scoliosis $\left(78^{\circ}\right.$ and $75^{\circ}$, respectively) suspected abnormalities of respiratory function and hypoplastic cardiac changes to be responsible. However, the early stages of the impact of scoliosis on respiratory system are not fully understood. Numerous mechanisms have been evoked: reduction of the volume of rib cage [11,34], decreased expansion of thoracic wall [7], or impairment of the respiratory muscles [18] by deformation of their architectural arrangement [9] or of patterns of activation [29].

Disorders in chest mechanics, impaired mobility of rib and vertebra joints and impaired rib amplitudes were reported by Durmala and Tomalak [12], Durmała et al. [13], Gnat et al. [14], Koumbourlis [21] as well as Ramirez et al. [26]. Apart from restrictions in chest mobility and flexibility, the authors observed weakening of the main and auxiliary respiratory muscles in children and adolescents with idiopathic scoliosis. This leads to shallowness of breath, increased frequency as well as disproportions between inspiration and expiration [8]. Taking into consideration the consequences of idiopathic scoliosis on the functions of cardiovascular and respiratory systems and its common occurrence among children and adolescents and, especially girls, it seems important to monitor the cardiovascular and respiratory capacity in children with idiopathic scoliosis [23, 25, 33].

The choice of both the proper method of $V_{2} \max$ assessment and the kind of ergometer during tolerance tests with children should be determined by the following factors: the possibility of objective, reliable measurement of the examined parameters, ensuring safety during tolerance tests and providing for the specific character of tolerance tests in children $[15,24,30]$.

The most widely known parameter of physical capacity is the maximum oxygen intake $\left(\mathrm{VO}_{2} \mathrm{max}\right)$. It indicates the maximum oxygen capacity absorbed by the organism per minute during dynamic physical effort [3, 16, 30]. The
Table 4 Spearman's correlation of the curvature angle versus the measured parameters $V \mathrm{O}_{2} \max , R V \mathrm{O}_{2} \max$ and PWC170 in the mild and moderate scoliosis group

\begin{tabular}{llll}
\hline & $n$ & $\begin{array}{l}\text { Spearman's } \\
\text { coefficient } \\
R\end{array}$ & $p$ value \\
& 70 & -0.196 & 0.1 \\
\hline$V \mathrm{O}_{2} \mathrm{max}(\mathrm{l} / \mathrm{min}) \&$ curvature angle & 70 & -0.232 & 0.05 \\
$\begin{array}{l}R V \mathrm{O}_{2} \mathrm{max}(\mathrm{ml} / \mathrm{kg} / \mathrm{min}) \& \text { curvature } \\
\text { angle }\end{array}$ & 70 & -0.204 & 0.08 \\
PWC170 (W) \& curvature angle & 70 & -0.273 & 0.02 \\
PWC170 (W/kg) \& curvature angle & &
\end{tabular}

' $\&$ ' refers to the parameters with the examined correlation. Significant differences are marked in italic

measure of reaching $V \mathrm{O}_{2}$ max during the effort is the absence of increased oxygen intake $\left(\mathrm{VO}_{2}\right.$ reaches plateau) despite the effort. The result is rarely recorded in children [16, 24, 30]. Nixon et al. [24] as well as Teoh et al. [30] maintain that the attempts to record stabilized oxygen intake for two subsequent efforts are rarely successful in children, which is caused by the fact that children lack the proper motivation to make the maximal effort as well as their lack of cooperation.

The indirect methods are widely applied in the diagnosis of physical capacity in children, adolescents and adults either with or without idiopathic scoliosis. Especially submaximal tests are more accepted by children [6, 20, 24, 30].

Many researchers [3, 19, 28] emphasize the significance of correlations between oxygen intake and the heart rate-a precise and objective value to determine the maximum oxygen intake-in conditions of functional equilibrium under submaximal strain. One of the tests belonging to the indirect method group is the PWC170 test. According to Karpman [19], the higher the value of this indicator, the more strenuous effort a person can make without any disturbance to the cardiovascular system functioning. Thus, the greater the value of the PWC170 indicator is, the better the physical capacity is. This correlation is confirmed by the value of the PWC170 indicator and the maximum oxygen intake.

In order to assess physical capacity, the submaximal exercise test on the cycling ergometer was applied along 
Table 5 Comparison of $V \mathrm{O}_{2} \max (1 / \mathrm{min}), R V \mathrm{O}_{2} \max (\mathrm{ml} / \mathrm{kg} / \mathrm{min})$ and $\mathrm{PWC} 170$ index $(\mathrm{W} ; \mathrm{W} / \mathrm{kg})$ in the group of girls with IS as well as the number of vertebrae below and equal and above the average and the control group

\begin{tabular}{lccccc}
\hline & $\begin{array}{l}\text { Below and equal } \\
\text { average }(\leq 9) \\
(n=33)\end{array}$ & $\begin{array}{l}\text { Above average } \\
(>9)(n=37)\end{array}$ & $\begin{array}{l}\text { Control group } \\
(n=27)\end{array}$ & $p$ value & Dunn's test \\
\hline$V \mathrm{O}_{2} \max (1 / \mathrm{min})$ & $2.0(0.16)$ & $1.93(0.12)$ & $2.03(0.1)$ & 0.06 & - \\
$R V \mathrm{O}_{2} \mathrm{max}(\mathrm{ml} / \mathrm{kg} / \mathrm{min})$ & $42.23(9.8)$ & $41.8(8.1)$ & $44.41(8.6)$ & 0.38 & - \\
$\mathrm{PWC170}(\mathrm{W})$ & $74.45(16.3)$ & $68.02(11.8)$ & $77.35(18.4)$ & 0.06 & - \\
$\mathrm{PWC170}(\mathrm{W} / \mathrm{kg})$ & $1.59(0.5)$ & $1.46(0.3)$ & $1.68(0.3)$ & 0.01 & Above average $<$ Control \\
\hline
\end{tabular}

The values presented as mean (SD). Significant difference is marked in italic

with the PWC170 test. A similar solution was applied by Cleland et al. [6] as well as Trudeau et al. [31]. Tests on the cycling ergometer prevent intensive movement of the upper body, provide the possibility of safe discontinuation and easy control over the increase of strain. Taking into consideration the fact that the ability to ride a bicycle is widespread, this can be easily adapted to the specificity of stationary cycling and there is a seat adjustable to the height of a child, a cycling ergometer is a safe, widely accepted and precise measuring apparatus [6, 15, 24, 31].

It seems desirable to introduce assessment of the physical capacity into the physiotherapy program for girls with idiopathic scoliosis. However, the currently conducted assessment of the correlation between idiopathic scoliosis and physical capacity seems incomplete. The majority of authors involved in this problem focus on the spine deformation as a whole, accepting the angle of curvature as the sole criterion for classification. The hypothesis that the increase of the angle of curvature entails significant decrease of the physical capacity was confirmed by Schneerson and Madgwick [27] who used the exercise test on the cycling ergometer, DiRocco et al. [10], who subjected children and adolescents aged 10-17 to the increasing effort test, and also by Barrios and PerezEncinas [4]. Although the results obtained with different research records should not be compared directly, it is worth noting that all the authors observed a similar correlation.

The authors of this study did not confirm any significant correlation between the angle of curvature and the parameters describing the physical capacity $\left(\mathrm{VO}_{2} \max\right.$, $R V \mathrm{O}_{2}$ max). It most probably stems from the fact that the girls included in the observation had mild and moderate scoliosis. However, a significant decrease in the maximum oxygen intake $(1 / \mathrm{min})$ and the PWC170 indicator was observed in girls with scoliosis ranking from $25^{\circ}$ to $40^{\circ}$ in relation to the control group.

Curvature value exceeding $25^{\circ}$ in the pubertal growing phase is usually considered an indication for the treatment by means of a brace [33]. Therefore, lowering the physical
Table 6 Spearman's correlation between the number of scoliotic vertebrae and the measured parameters: $V \mathrm{O}_{2} \max , R V \mathrm{O}_{2} \max$ and PWC170 in the scoliosis group

\begin{tabular}{llll}
\hline & $n$ & $\begin{array}{l}\text { Spearman's } \\
\text { coefficient } R\end{array}$ & $p$ value \\
\hline $\begin{array}{l}V \mathrm{O}_{2} \text { max }(1 / \mathrm{min}) \& \text { number of } \\
\text { scoliotic vertebrae }\end{array}$ & 70 & -0.163 & 0.17 \\
$\begin{array}{l}R V \mathrm{O}_{2} \mathrm{max}(\mathrm{ml} / \mathrm{kg} / \mathrm{min}) \& \text { number of } \\
\text { scoliotic vertebrae }\end{array}$ & 70 & -0.196 & 0.79 \\
$\begin{array}{l}\mathrm{PWC170}(\mathrm{W}) \& \text { number of } \\
\quad \text { scoliotic vertebrae }\end{array}$ & 70 & -0.172 & 0.15 \\
$\begin{array}{l}\text { PWC170 (W/kg) \& number of } \\
\text { scoliotic vertebrae }\end{array}$ & 70 & -0.273 & 0.02 \\
\hline
\end{tabular}

' $\&$ ' refers to the parameters with the examined correlation. Significant difference is marked in italic

capacity and the effort adjustment capacity might be expected in patients with such an indication. In such cases, it is crucial to undertake proper diagnostic and therapeutic steps.

In order to obtain a full picture of the impact of idiopathic scoliosis on the physical capacity in children and adolescents and their abilities to adjust their physical efforts, it is necessary to investigate the impact of various features characterizing scoliosis. In their research, Durmała et al. [13] observed the disturbances of orientation along the axis of ribs and vertebra joints. Thus, the number of vertebrae included in scoliotic deformation can influence chest mobility, and directly, physical capacity. The number of curvatures, in turn, is connected not only with the size of deformation but also with the risk of progression, which can also have an impact on cardiovascular and respiratory capacity. A very important problem in the treatment of idiopathic scoliosis is the phenomenon of compensation. Single-curve scoliosis is usually connected with a large trunk decompensation, which can cause decreased physical fitness in girls with idiopathic scoliosis. This may lead to impairment of physical capacity and decrease the ability to adjust to strain [33]. However, the biography analyzed by the authors lacks information about the 
Table 7 Comparison of $V \mathrm{O}_{2} \max (1 / \mathrm{min}), R V \mathrm{O}_{2} \max (\mathrm{ml} / \mathrm{kg} / \mathrm{min})$ and $\mathrm{PWC} 170$ index $(\mathrm{W} ; \mathrm{W} / \mathrm{kg})$ in the group of girls with single-curve scoliosis, double-curve scoliosis and the control group

\begin{tabular}{lccccc}
\hline & Single-curve $(n=34)$ & Double-curve $(n=36)$ & Control group $(n=28)$ & $p$ value & Dunn's test \\
\hline$V \mathrm{O}_{2} \max (1 / \mathrm{min})$ & $1.99(0.16)$ & $1.94(0.12)$ & $2.03(0.1)$ & 0.13 & - \\
$R V \mathrm{O}_{2} \mathrm{max}(\mathrm{ml} / \mathrm{kg} / \mathrm{min})$ & $42.15(9.7)$ & $41.83(8.1)$ & $44.41(8.6)$ & 0.38 & - \\
$\mathrm{PWC170}(\mathrm{W})$ & $73.41(15.9)$ & $68.82(11.8)$ & $77.35(18.4)$ & 0.11 & - \\
$\mathrm{PWC170}(\mathrm{W} / \mathrm{kg})$ & $1.57(0.5)$ & $1.47(0.3)$ & $1.68(0.3)$ & 0.01 & Double $<$ Control \\
\hline
\end{tabular}

The values presented as mean (SD). Significant difference is marked in italic

relationships between the number of scoliotic vertebrae, the number of curvatures and the physical capacity. This is the reason why the authors' intention was to assess those relationships.

The conducted research, however, presents the relationships between the number of scoliotic vertebrae, curvatures and physical capacity in an equivocal way. Out of all the parameters determining physical capacity, only one was proven to decrease the PWC170 (W/kg). This parameter was lower both in the case of girls with the number of scoliotic vertebrae, that is less than average, and in the case of double-curve scoliosis. Therefore, we might expect the angle value to have a dominant impact on the physical capacity of girls with mild and moderate idiopathic scoliosis.

\section{Conclusions}

1. The maximum oxygen intake and the output during the PWC170 test is lower in girls with moderate scoliosis $\left(25^{\circ}-40^{\circ}\right)$ than in the control group.

2. The value of maximum oxygen intake and output obtained during the PWC170 test in girls with mild scoliosis (up to $25^{\circ}$ ) does not differ significantly from the values obtained in the control group.

3. The number of vertebrae involved in scoliotic deformation and the number of curvatures cause significant decrease in only the relative value of the output obtained during an exercise test. The number of scoliotic vertebrae and the number of curvatures do not influence the maximal oxygen intake and the absolute value of PWC170 indicator.

Acknowledgments No grants were received in support of this manuscript.

Conflict of interest The authors declare that no conflict of interest occurs.

Open Access This article is distributed under the terms of the Creative Commons Attribution Noncommercial License which permits any noncommercial use, distribution, and reproduction in any medium, provided the original author(s) and source are credited.

\section{References}

1. Alves dos Santos VL (2006) Physical rehab improves respiratory function in teens with scoliosis. Chest 130:500-505. doi:10.1378/ chest.130.2.500

2. Asher MA, Burton DC (2006) Adolescent idiopathic scoliosis: natural history and long term treatment effects. Scoliosis 1:1. doi:10.1186/1748-7161-1-2

3. Astrand PO, Rodahl K (1986) Textbook of work physiology. McGraw Hill, New York

4. Barrios C, Perez-Encinas C (2005) Significant ventilatory functional restriction in adolescents with mild or moderate scoliosis during maximal exercise tolerance test. Spine 30:1610-1615. doi: 10.1097/01.brs.0000169447.55556.01

5. Busscher I, Gerver WJM, Kingma I, Wapstra FH, Verkerke GJ, Veldhuizen AG (2011) The growth of different body length dimensions is not predictive for the peak growth velocity of sitting height in the individual child. Eur Spine J 20:791-797. doi: 10.0007/s00586-010-1584-6

6. Cleland V, Wyder T, Blizzard L, Venn A (2008) The provision of compulsory school physical activity: Associations with physical activity, fitness and overweight in childhood and twenty years later. Int J Behav Nutr Phys Act 5:14. doi:10.1186/1479-58685-14

7. Cline CC, Coast JR, Amall DA (1999) A chest wall restrictor to study effects on pulmonary function and exercise. Respiration 66:182-187

8. Coast JR, Cline CC (2004) The effect of chest wall restriction on exercise capacity. Respirology 9:197-203

9. Cooper DM, Rojas JV, Mellins RB, Keim HA, Mansell AL (1984) Respiratory mechanics in adolescents with idiopathic scoliosis. Am Rev Respir Dis 130:16-22

10. DiRocco PJ, Vaccaro P (1988) Cardiopulmonary functioning in adolescent patients with mild idiopathic scoliosis. Arch Phys Med Rehabil 69:198-201

11. Dubousset J (1994) Three-dimensional analysis of the scoliotic deformity. In: Weinstein SL (ed) The pediatric spine. Raven Press, New York, pp 479-496

12. Durmala J, Tomalak W (2007) Respiratory muscle strength in adolescents with idiopathic scoliosis. Scoliosis 2(Suppl 1):S4. doi:10.1186/1748-7161-2-S1-S4

13. Durmała J, Tomalak W, Kotwicki T (2008) Function of the respiratory system in patients with idiopathic scoliosis: reasons for impairment and methods of evaluation. Stud Health Technol Inform 135:237-245 
14. Gnat R, Saulicz E, Ryngier P, Zięba M (2003) Changes of values of selected spirometric parameters in course of complex rehabilitation treatment in patients with scoliosis of $\mathrm{I}^{\circ}$ and $\mathrm{II}^{\circ}$. Pol $\mathrm{J}$ Physiother 3:21-29

15. Grant S, Corbett K, Amjad AM, Wilson J, Aitchison T (1995) A comparison of methods of predicting maximum oxygen uptake. Br J Sports Med 29:147-152. doi:10.1136/bjsm.29.3.147

16. Hawkins MN, Raven PB, Snell PG (2007) Maximal oxygen uptake as a parametric measure of cardiorespiratory capacity. Med Sci Sorts Exerc 39:103-107. doi:10.1249/01.mss.000024 1641.75101 .64

17. Hitosugi M, Shigata A, Takatsu A (2000) An autopsy case of sudden death in a patient with idiopathic scoliosis. Med Sci Law 40(2): $175-178$

18. Jones RS, Kennedy JD, Hasham F, Owen R, Taylor JF (1981) Mechanical inefficiency of the thoracic cage in scoliosis. Thorax 36:456-461

19. Karpman VL (1987) Cardiovascular system and physical exercise. CRC Press, Boca Raton

20. Kearon C, Viviani GR, Kilian KJ (1993) Factors influencing work capacity in adolescent idiopathic thoracic scoliosis. Am Rev Respir Dis 148:295-303

21. Koumbourlis AC (2006) Scoliosis and the respiratory system. Paediatr Respir Rev 7:152-160

22. Mauroy JC (2008) Idiopathic Scoliosis and Chaos. In: Grivas TB (ed) Conservative scoliosis treatment. IOS Press, Amsterdam, pp 53-57

23. Newton PO, Perry A, Bastrom TP, Lenke LG, Betz RR, Clements DD, Andrea L (2007) Predictors of change in postoperative pulmonary function in adolescent idiopathic scoliosis. A prospective study of 254 patients. Spine 32:1875-1882. doi:10.1097/brs. 0b013e31811eab09

24. Nixon PA, Orenstein DM (1988) Exercise testing in children. Pediatr Pulmonol 5:107-122

25. Pehrsson K, Danielsson A, Nachemson A (2001) Pulmonary function in adolescent idiopathic scoliosis: a 25 year follow-up after surgery or start of brace treatment. Thorax 56:388-393. doi:101136/thorax.56.5.388

26. Ramirez M, Martinem J, Molina A (2006) Decrease of the strength and resistance of the respiratory muscles in patients with AIS and Cobb $>45$ impaired exercise capacity. J Bone Joint Surg 88-B(Suppl 1):146

27. Schneerson JM, Madgwick R (1979) The effect of physical training on exercise ability in adolescent idiopathic scoliosis. Acta Orthop 50:303-306

28. Sjostrand T (1967) Clinical cardiopulmonary physiology. Grune Straton, New York

29. Smyth RJ, Chapman KR, Wright TA, Crawford JS, Rebuck AS (1986) Ventilatory patterns during hypoxia, hypercapnia and exercise in adolescents with mild scoliosis. Paediatrics 77: 692-697

30. Teoh OH, Trajsel D, Mei-Zahav M, Selvadurai H (2009) Exercise testing in children with lung diseases. Paediatr Respir Rev 10:99-104. doi:10.1016/j.prrr.2009.06.004

31. Trudeau F, Shephard RJ, Arsenault F, Laurencelle L (2003) Tracking of physical fitness from childhood to adulthood. Can J Appl Physiol 28(2):257-271

32. Wang W, Hung VWY, Lam TP, Ng BKW, Qin L, Lee KM, Qiu Y, Cheng JCY, Yeung HY (2010) The association of disproportionate skeletal growth and abnormal radius dimension ratio with curve severity in adolescent idiopathic scoliosis. Eur Spine J 19:726-731. doi:10.0007/s00586-009-1247-7

33. Weiss HR, Negrini S, Hawes M, Rigo M, Kotwicki T, Grivas TB, Maruyama T (2006) Physical exercises in the treatment of idiopathic scoliosis at risk of brace treatment-SOSORT consensus paper 2005. Scoliosis 1:6. doi:10.1186/1748-7161-1-6

34. Winter RB, Lovell WW, Moe JH (1975) Excessive thoracic lordosis and loss of pulmonary function in patients with idiopathic scoliosis. J Bone Joint Surg 57-A:972-977 